\title{
COVID-19 Pneumonia during Hydroxychloroquine Treatment of Rheumatoid Arthritis
}

\author{
Canan Gürsoy ${ }^{1}$, Özge Oral Tapan², Emrah Dogan ${ }^{3}$, Turhan Togan ${ }^{4}$ and Semra Gumus Demirbilek ${ }^{1}$ \\ ${ }^{1}$ Department of Anesthesiology and Reanimation, Division of Intensive Care Unit, Muğla Sıtkı Koçman University Training and Research \\ Hospital, Muğla, Turkey \\ ${ }^{2}$ Department of Lung Diseases, Muğla Sitkı Koçman University, Muğla, Turkey \\ ${ }^{3}$ Department of Radiology, Muğla Sitkı Koçman University, Muğla, Turkey \\ ${ }^{4}$ Department of Infection Diseases, Muğla Sitkı Koçman University, Muğla, Turkey
}

\begin{abstract}
The recently emerged and novel coronavirus, severe acute respiratory distress syndrome coronavirus 2 (SARS-CoV-2), that caused the current global pandemic was detected for the first time in Turkey in March 2020. While it continues to spread rapidly worldwide, there are still many uncertainties in the prevention and treatment of new coronavirus disease. We report a case of coronavirus disease 2019 (COVID-19) pneumonia in a patient under hydroxychloroquine (HCQ) treatment for rheumatoid arthritis. A 38-year female patient developed severe respiratory distress with SARS-CoV-2 infection and was treated in Intensive Care Unit (ICU). With this report, we aim to discuss the place of HCQ in prophylaxis in the light of the literature with a case presentation of COVID-19 pneumonia under HCQ treatment.
\end{abstract}

Key Words: Coronavirus, Hydroxychloroquine, Prophylaxis, Rheumatoid arthritis, COVI-19.

How to cite this article: Gürsoy C, Tapan ?O, Dogan E, Togan T, Demirbilek SG. COVID-19 Pneumonia during Hydroxychloroquine Treatment of Rheumatoid Arthritis. J Coll Physicians Surg Pak 2020; 30(JCPSPCR):CR168-CR170 .

\section{INTRODUCTION}

The recently emerged novel coronavirus, severe acute respiratory distress syndrome coronavirus 2 (SARS-COV-2), causing the current global pandemic was first detected in Turkey in March 2020. While it continues to spread rapidly worldwide, there are still many uncertainties in the prevention and treatment of novel coronavirus disease 2019 (COVID-19). In addition to efforts about developing new drugs specific to SARS-CoV-2, in vitro studies are investigating the effects of existing drugs. Remdesivir, chloroquine (CQ) and hydroxychloroquine (HCQ) are the most populardrugs in this regard. ${ }^{1}$

Healthcare workers infected during respiratory invasive procedures (i.e. intubation, endotracheal tube aspiration or bronchoscopy) obviously can be a source of infection in asymptomatic or pre-symptomatic periods for patients who have a medical care requirement not related to each other, their families and SARS-CoV-2.

Correspondence to: Dr. Canan Gürsoy, Department of Anesthesiology and Reanimation, Division of Intensive Care Unit, Muğla Sitkı Koçman University Training and Research Hospital, Muğla, Turkey

E-mail: gursoycanan@yahoo.com

Received: May 21, 2020; Revised: July 17, 2020;

Accepted: October 24, 2020

DOI: https://doi.org/10.29271/jcpsp.2020.JCPSPCR.CR168
Therefore, the use of prophylactic drugs has a crucialplace among the strategies developed for the prevention of transmission. CQ/HCQ are known as anti-malarials for more than 70 years. Due to the fact thatthere is not enough evidence with regard to their mechanism of action against SARS-CoV-2, theiruse in prophylaxis has been questioned. ${ }^{1}$

In this report, we aim to discuss the place of HCQ in prophylaxis in the light of the literature with a case presentation of COVID-19 pneumonia under HCQ treatment.

\section{CASE REPORT}

A 38-year female patient admitted to the hospital with the complaints of fever, cough, widespread muscle pain and dyspnoea; and was hospitalised after the computed tomography of the lung, which was compatible with COVID-19 and interstitial alveolar haemorrhage (IHA) (Figure 1). The patient developed severe respiratory distress within 24 hours and was intubated and taken to mechanical ventilation support, before transferring to ICU. In hermedical history, she hadrheumatoid arthritis and IHA disease and had been using $400 \mathrm{mg} /$ day HCQas treatment for the last one year. Oseltamivir (150mg/day), and meropenem (3g/day) was started in ICU and HCQ(400 mg/day) was continued.

The patient, who developed moderate acute respiratory distress syndrome (ARDS) was followed up with 8 days' mechanical ventilation support. Clinical course and treatment of the patient are given in Table land laboratory findings are given in Tablell. 
Table I: Clinical course, treatment and viral load of the patient.

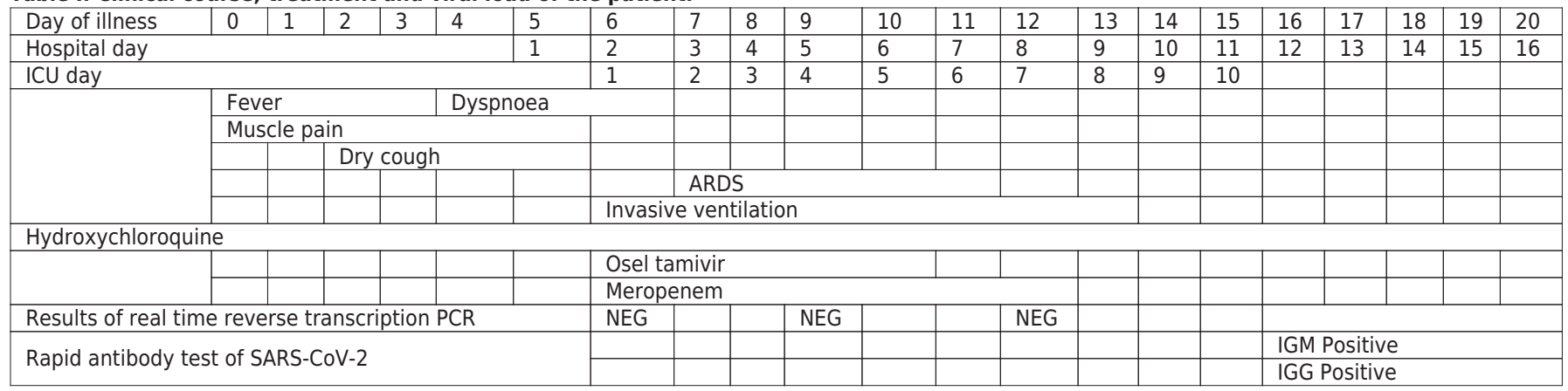

Table II: Serial laboratory results of the patient.

\begin{tabular}{|c|c|c|c|c|c|}
\hline Day of IIIness & IIIness day 6 & Illness day 10 & IIIness day 14 & Illness day 18 & Illness day 20 \\
\hline Hospital day & HD 1 & HD 6 & HD 11 & HD 14 & HD 16 \\
\hline ICU day & ICU day 2 & ICU day 5 & ICU day 10 & & \\
\hline $\mathrm{PaO} 2 / \mathrm{FIO} 2$ & 135 & 250 & $>400$ & - & - \\
\hline Lactate & 2.5 & 1,9 & 0,4 & - & - \\
\hline White Blood Cell Count, $\times 10^{3} / \mathrm{ml}$ & 15,69 & 14,9 & 15,8 & 14,95 & 16,0 \\
\hline Lymphocyte, \% & 5.4 & 1,4 & 7,9 & 15,3 & 17,3 \\
\hline Segment of Neutrophil, \% & 86,5 & 92,5 & 86,7 & 96,7 & 88,6 \\
\hline Hemoglobin, g/dl & 9.5 & 8,9 & 9,3 & 10,1 & 11 \\
\hline Plateles, $\times 10^{3} / \mathrm{ml}$ & 294 & 248 & 294 & 349 & 334 \\
\hline Glucose, mg/dl & 201 & 120 & 126 & 141 & 138 \\
\hline Creatinine, mg/dl & 1,09 & 0,98 & 0,45 & 0,52 & 0,48 \\
\hline BUN, mg/dl & 48 & 43 & 43,5 & 49 & 58,9 \\
\hline AST, U/L & 39 & 92 & 94 & 75 & 34 \\
\hline $\mathrm{ALT}, \mathrm{U} / \mathrm{L}$ & 16 & 68 & 34 & 35 & 50 \\
\hline Albumine, $\mathrm{g} / \mathrm{dl}$ & 40 & 33 & 29 & 30 & 34 \\
\hline $\mathrm{CK}, \mathrm{U} / \mathrm{L}$ & 131 & 2293 & 1951 & 592 & 296 \\
\hline $\mathrm{LDH}, \mathrm{U} / \mathrm{L}$ & 1053 & 641 & 708 & 409 & 479 \\
\hline $\mathrm{CRP}, \mathrm{mg} / \mathrm{dl}$ & 85 & 45 & 16 & 7,8 & 5,26 \\
\hline Procalcitonin, $\mathrm{ng} / \mathrm{ml}$ & 0.508 & 0,094 & - & - & $<0,05$ \\
\hline PT, sec & 14,3 & 13 & 12,5 & 14,1 & 12,8 \\
\hline PT, INR & 1,29 & 1,14 & 1,1 & 1,24 & 1,13 \\
\hline aPTT, sec & 65 & 17 & 17,7 & 17,4 & 18 \\
\hline Ferritin & 88,8 & & & & 119 \\
\hline D-dimer, $\mathrm{mg} / \mathrm{ml}$ & 735 & 4612 & 5364 & 3852 & \\
\hline
\end{tabular}

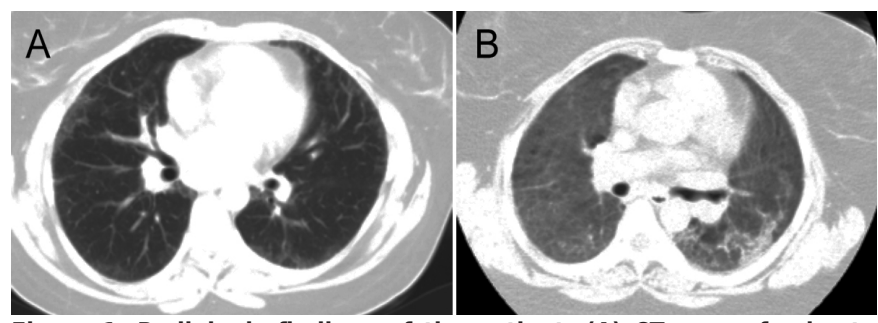

Figure 1: Radiologic findings of the patient; (A) CT scan of prior to COVID-19 pneumonia (date, 2019) (B) CT scan of illness day 6, hospital day.

Other viral and bacterial pathogens wereexcluded for the moderate ARDS ( $\mathrm{PaO} 2<100 / \mathrm{FIO}<200)$. Haemoptysis was not observed in ICUfollow-up. The SARS-CoV-2 real time-polymerase chain reaction (RT-PCR) test results were negative. However, because clinical and CT findings werecompatible with COVID-19, rapid antibody test of SARS-CoV-2 was studied and it has shown to be immunoglobulin (Ig)M-IgG positive.
The patient was discharged from ICU on 10th day of hospitalisation, and from the hospital on 16th day with recovery.

\section{DISCUSSION}

The rapid spread of SARS-COV-2 in China has resulted in a search for an effective drug that can treat symptomatic patients. This drug should reduce the virus transmission time as well as side effects, be safe and with effective antiviral properties. As information about the replication of the virus becomes clear, in vitro studies gained speed and CQ/HCQ have been found to be effective against SARS-CoV-2, ${ }^{2,3}$

It is known that CQ/HCQ are able to inhibit replication at early phase of viral infection, increasing endosomal $\mathrm{pH}$, inhibiting autophagosome-lysosome fusion and inactivating enzymes at the time of coronavirus-human cell fusion. ${ }^{4}$ In the case of COVID-19, Wang et al. demonstrated with timeof-assay that CQ functioned at both entry and at post-entry stages of infection in the VERO E6 cells assay. ${ }^{2}$ Other in 
vitro studies have shown that the glycosylation process of the angiotensin converting enzyme 2 (ACE2) receptor gets affected, thus causing the VERO cells pre-treated with CQ to be refractory to SARS-CoV infection. ${ }^{2-5}$ The SARS-CoV-2 is known to bind to human cells via ACE 2 receptors. ${ }^{6}$ Due to the above-mentioned effects of CQ/HCQ against SARS-CoV-2, theiruse in pre-exposure and post-exposure prophylaxis has begun to be discussed.

Despite all these mechanisms, COVID-19 with moderate ARDS developed under HCQ treatment in thiscase.Despite the lung pathology, the patient's clinical condition improved rapidly. This may partly be explained by the fact that the patient was receiving HCQ both pre-exposure and post-exposure to virus infection. However, HCQ was not completely successful in preventing infection by SARS-CoV-2. This demonstration raisessome scepticism regarding the effectiveness of HCQ in SARS-CoV-2 prophylaxis.

Currently, there are no randomised clinical trials (RCTs) to provide clinical guidance on the use, dose, and duration of $\mathrm{CQ} / \mathrm{HCQ}$. But many are planned or are underway to study CQ and HCQ for treating and preventing COVID-19 in different countries (examples: NCT04315896, NCT04318015, NCT04318444, NCT04321278, NCT04308668, NCT04304053, NCT0431637 and NCT04303299). In the light of all these studies, we will have a better understanding of the use of $\mathrm{CQ} / \mathrm{HCQ}$ in prophylaxis in the future.

\section{CONFLICT OF INTEREST:}

The authors declared no conflict of interest.

\section{PATIENT'S CONSENT:}

Informed consent was obtained from the patient for publishing his details and data.

\section{AUTHORS' CONTRIBUTION:}

CG: Concept, design, definition and intellectual content, literature search, data acquisition, data analysis, and manuscript preparation and editing.

ÖOT, ED: Concept, design, data acquisition, data analysis.

$\Pi$ : Design, definition and intellectual content.

SGD: Concept, design, definition and intellectual content, manuscript preparation and editing.

\section{REFERENCES}

1. Gautret P, Lagier JC, Parola P, Hoang VT, Meddeb L, Mailhe $M$, et al. Hydroxychloroquine and azithromycin as a treatment of COVID-19: Results of an open-label non-randomised clinical trial. Int J Antimicrob Agents 2020; 56(1):105949. doi: 10.1016/j.ijantimicag.2020.105949.

2. Wang M, Cao R, Zhang L, Yang X, Liu J, Xu M, et al. Remdesivir and chloroquine effectively inhibit the recently emerged novel coronavirus (2019-nCoV) in vitro. Cell Res 2020; 30(3):269-71. doi: 10.1038/s41422-020- 0282-0.

3. Gao J, Tian Z, Yang X. Breakthrough: Chloroquine phosphate has shown apparent efficacy in treatment of COVID-19 associated pneumonia in clinical studies. Bioscience Trends 2020; 14(1):72-3. doi: 10.5582/bst. 2020.01047.

4. Zhou D, Dai SM, Tong Q. COVID-19: A recommendation to examine the effect of hydroxychloroquine in preventing infection and progression. J Antimicrob Chemother 2020; 75(7):1667-70. doi: 10.1093/jac/dkaa114.

5. Agrawal S, Goel AD, Gupta N. Emerging prophylaxis strategies against COVID-19. Monaldi Arch Chest Dis 2020; 90(1). doi: 10.4081/monaldi.2020.1289.

6. Savarino A, Boelaert JR, Cassone A, Majori G, Cauda R. Effects of chloroquine on viral infections: An old drug against today's diseases? Lancet Infect Dis 2003; 3(11): 722-7. doi: 10.1016/s1473-3099(03)00806-5. 